\title{
Spontaneous Regression of Primary Thyroid Lymphoma: Two Rarities at the Same Time
}

\author{
Francisco ILLÁN-GAMBíN ${ }^{1}$ (D), Pablo MANRESA-MANRESA² (D, Estefanía RODRÍGUEZ-ALEO, \\ Ignacio ARANDA-LÓPEZ'
}

Department of ${ }^{1}$ Pathology, ${ }^{2}$ Hematology and ${ }^{3}$ Nursing Department, University General Hospital of Alicante, ALICANTE, SPAIN

\begin{abstract}
Primary thyroid lymphomas are pretty uncommon, and constitute about $5 \%$ of the neoplasms of this organ. Spontaneous tumor regression is defined as the total or partial disappearance of a tumor as proven by microscope without treatment or under inadequate treatment. It is estimated to happen in one out of 60,000-100,000 cases. We present a case of primary thyroid lymphoma with spontaneous regression after diagnostic puncture and corroborated with hemithyroidectomy at four months. The patient died after twenty-six months of follow-up because of endocarditis and there was no relapse at any time.
\end{abstract}

Key Words: Lymphoma, Thyroid neoplasms, Spontaneous neoplasm regression, PD-L1

\section{INTRODUCTION}

Primary thyroid lymphomas constitute about $5 \%$ of all primary thyroid neoplasms and around $2 \%$ of extranodal lymphomas. The prototype patient is a woman (up to 4 times more frequent than in men) around the sixth decade of life. As regards histological subtypes, diffuse large B-cell lymphoma and marginal zone lymphoma are the most common (1). Spontaneous tumor regression (STR) is defined as the total or partial disappearance of a tumor validated microscopically without treatment or under inadequate treatment. It is estimated to happen in one out of 60,000-100,000 cases, although it probably appears more often. It is difficult to study STR because of its low prevalence. In addition, regressive changes are usually does not reported when they are presented in a partial way (2). Among solid tumors, melanoma seems to have STR most frequently. Regarding lymphomas, low grade types are more likely to regress but it is exceptional in those of high grade (3).

\section{CASE REPORT}

A 63-year-old woman had been followed-up for the last year because of subclinical hypothyroidism. She had been surgically treated for tonsils in childhood and for her gallbladder due to stones, and for aortic-mitral double replacement 20 years ago secondary to endocarditis. Because of the last one, she was anticoagulated with warfarin. Suddenly, she noted a nodule in the front of the

(Turk Patoloji Derg 2020, 36:164-168)

Received : 10.09.2018 Accepted : 12.10.2018 neck that became visible, without any other symptoms. The ultrasound showed a right thyroid lobe replaced by a solid and heterogeneous tumor of $4.4 \times 3.4 \mathrm{~cm}$ with ill-defined contours and abnormal vascularization with Doppler (Figure 1A). The patient underwent an extraclinical fineneedle aspiration (FNA) which displayed lymphocytes and large blastic-type cellularity with dispersed epithelial elements suggestive of thyroiditis but lymphoproliferative disorder could not be ruled out. Then she was referred to our hospital for a needle biopsy (16G).

The tissue showed a diffuse infiltrate of lymphoid large cells with lobulated nuclei, marked nucleoli, frequent mitosis and apoptosis. With broad-spectrum cytokeratins (CK AE1-AE3), nests of dispersed thyroid epithelium were identified. After immunohistochemical evaluation, the lymphoid nature of the neoplasm $(\mathrm{CD} 45+)$ was confirmed. It showed germinal center lymphocyte B-cell differentiation $(\mathrm{CD} 20+, \mathrm{CD} 10+, \mathrm{BCL}-2+, \mathrm{MUM} 1+, \mathrm{BCL}-6$ - and c-MYC -) and it had accompanying T lymphocytes $(\mathrm{CD} 3+)$. The proliferation index with Ki67 was greater than 80\% (Figure $2 \mathrm{~A}-\mathrm{F}$ ) and the immunoglobulin chain rearrangement analysis showed IgH clonality. Staining for PD-L1 (clone 22C3) showed low expression in atypical lymphoid cells (1-2\%). As there was no adenopathy or alterations on the imaging tests (including PET/CT), the diagnosis of primary thyroid diffuse large B-cell lymphoma, germinal center B-cell subtype (WHO, 2017) was made.
Correspondence: Francisco ILLÁN-GAMBíN

Department of Pathology, University General Hospital of Alicante ALICANTE, SPAIN

E-mail: fjig90@gmail.com Phone: +34965933044 
At the time of staging, two months after the first FNA, a clinical decrease of tumor dimensions was observed so a new ultrasound was performed. It showed a nodule with the same characteristics as the previous one that now measured $2.5 \mathrm{~cm}$ (Figure 1B). A new biopsy was taken showing thyroid follicles, fibrous tracts and non-atypical small lymphocytes. There was also plasma cells and macrophages with no apparent neoplastic population. The absence of tumor cells was confirmed immunohistochemically (CD20 -, CYCLIN D1 -, CD5 - and CD10 -) with Ki67 less than $1 \%$ and a marked increase in the T-cell population (Figure 3A-D). Residual lymphocytes showed no morphological or immunohistochemical characteristics suggestive of any other type of lymphoma.

Finally, a hemithyroidectomy was carried out five months after the first FNA. The right hemithyroid had regular weight and dimensions and whitish fibrous bands without defined solid nodules. After microscopic examination, we showed thyroid follicles of variable sizes with lymphoid clusters and germinal centers as well as a fibrotic area with lymphocytes like scar tissue (Figure 4A-C). No neoplastic population was demonstrated in any slide and the genetic rearrangement did not indicate clonality.

The patient passed away twenty-six months after the diagnosis due to endocarditis and there was no clinical or radiological relapse. In addition, she had undergone a $\mathrm{PET} / \mathrm{CT}$ scan prior to her death which only showed the infectious cardiac focus without uptake elsewhere. No new treatments were added at any time.

\section{DISCUSSION}

The first cause of lymphoid infiltrate in the thyroid is autoimmune thyroiditis. Currently, it has become the most frequent autoimmune disease and the first cause of hypothyroidism (4). Microscopically it displays lymphocytic infiltration of the stroma with large germinal centers and thyroid follicles. The last ones can show variable degrees of activity with regenerative, oncocytic or atrophic changes (5). Among its complications are lympho- and myeloproliferative disorders, both systemic and primary in the gland, whose relative risk will increase 80 times (6) as well as papillary carcinomas (7). Regarding lymphomas developing on thyroiditis, the most frequent type is marginal zone. It shows a heterogeneous infiltrate with atypical small lymphocytes, centrocytes, immunoblasts and plasma cells that can colonize germinal centers (1).

Meanwhile, STR is a striking entity described by TC Everson and WH Cole in the second half of the 20th century. In their work the definition of STR was proposed for the first time as well as a review of cases published until then (8). Most hypotheses trying to explain it have been in agreement afterwards. Most advocate a massive release of heteroantigens after aggression on the tumor that would enhance the immune response against it. In this way, local or systemic infections, vaccination, contusion, biopsy and

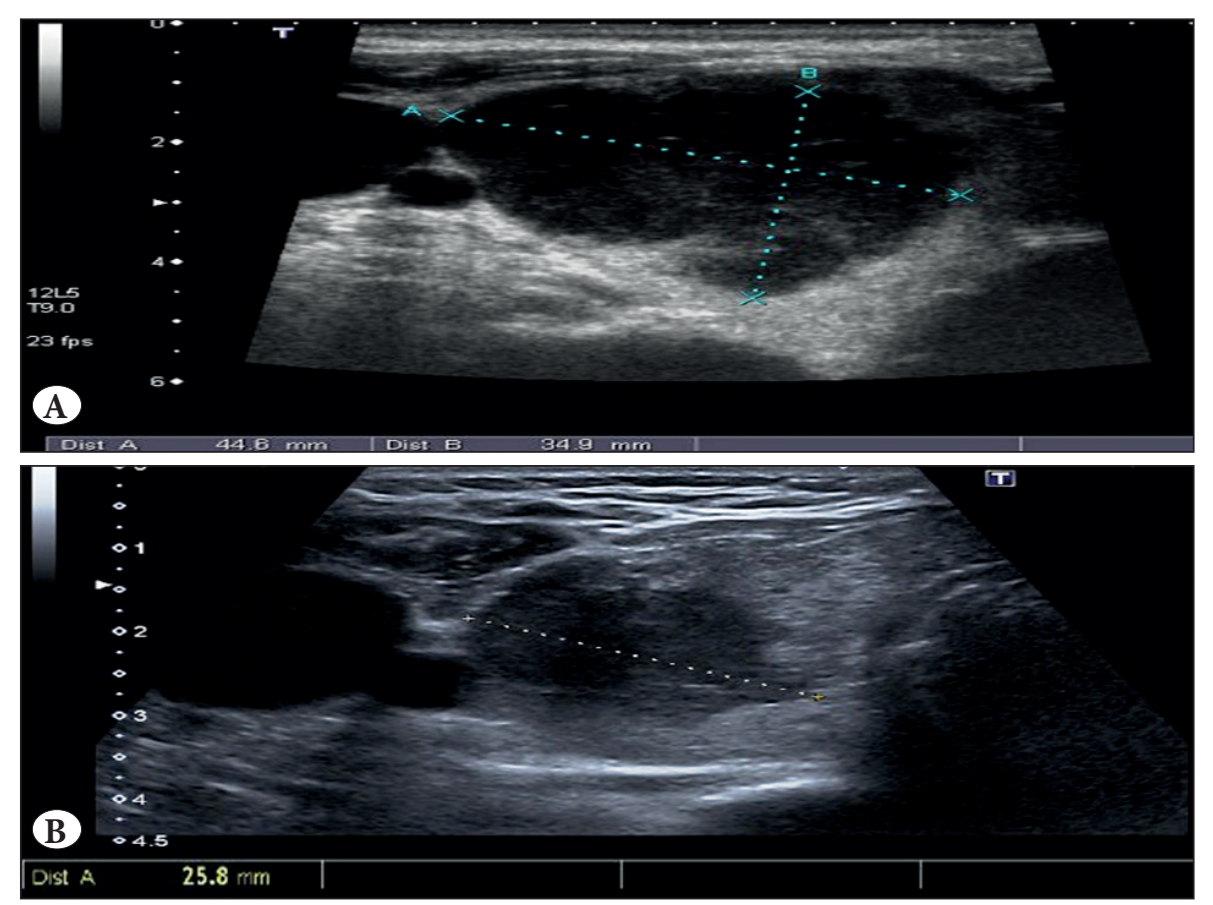

Figure 1: Right thyroid ultrasonography. The tests were performed two months apart. (upper: first ultrasonography). Note the tumor measures. 
even exposure to X-radiation could be triggers. Therefore, the most accepted theory to explain STR attributes is that the immune system plays the main role $(9,10)$. In the current case, we believe that FNA started the T-lymphocyte response that we found on needle biopsy and the surgical specimen and resulted in complete STR.

With reference to non-Hodgkin's lymphomas, some studies estimate $10-20 \%$ of STR in low-grade types but it is anecdotal in high-grade lymphomas. Immunoregulation has been considered important because regression of the lymphoma appears to a greater or lesser degree if T-mediated response is promoted on animal or in vitro models (after virus infection, addition of anti-idiotypic antibodies, cytokines, etc.) (11). There is also an association between the immunity status and the presence of some lymphoproliferative disorders as in AIDS patients, posttransplant lymphoproliferative disorders, and Epstein-Barr virus-associated lymphomas $(11,12)$.

Furthermore, it is known that thyroid lymphomas often show IgH clonality, especially in those from lymphocytic thyroiditis (1), although its prognostic role is unknown nowadays. We found only one published case of thyroid lymphoma regression in which immunoglobulin chain restriction was studied. This patient had IgH clonality and recurrence was earlier (13) as opposed to our case.

Finally, regarding PD-L1, its expression in lymphomas seems to inhibit T-cell activity against the tumor (14). In the present case, the low expression of PD-L1 could be a favorable point for the immune response against the neoplastic population.
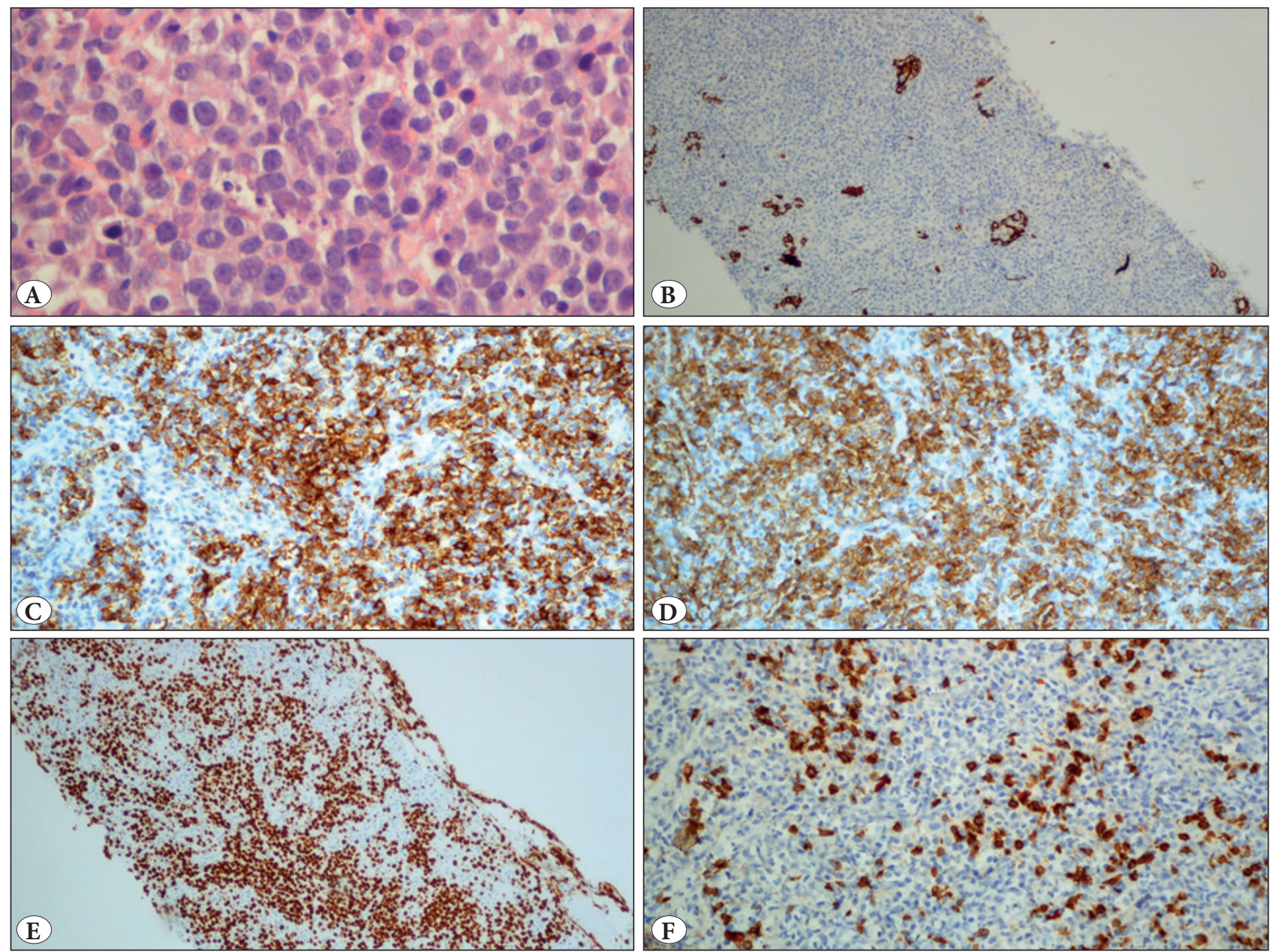

Figure 2: Primary thyroid diffuse large B-cell lymphoma. A) Lymphoid large cells with lobulated nuclei, marked nucleoli, frequent mitosis and apoptosis are present (H\&E; x 600). B) Nests of thyroid epithelium are identified (CKAE1/AE3; x100). C) Cells show positivity for CD20 (IHC; x200). D) Cells show positivity for CD10 (IHC; x200). E) High proliferation (Ki67; x100). F) There is accompanying T-lymphocytes (CD3; x200). 

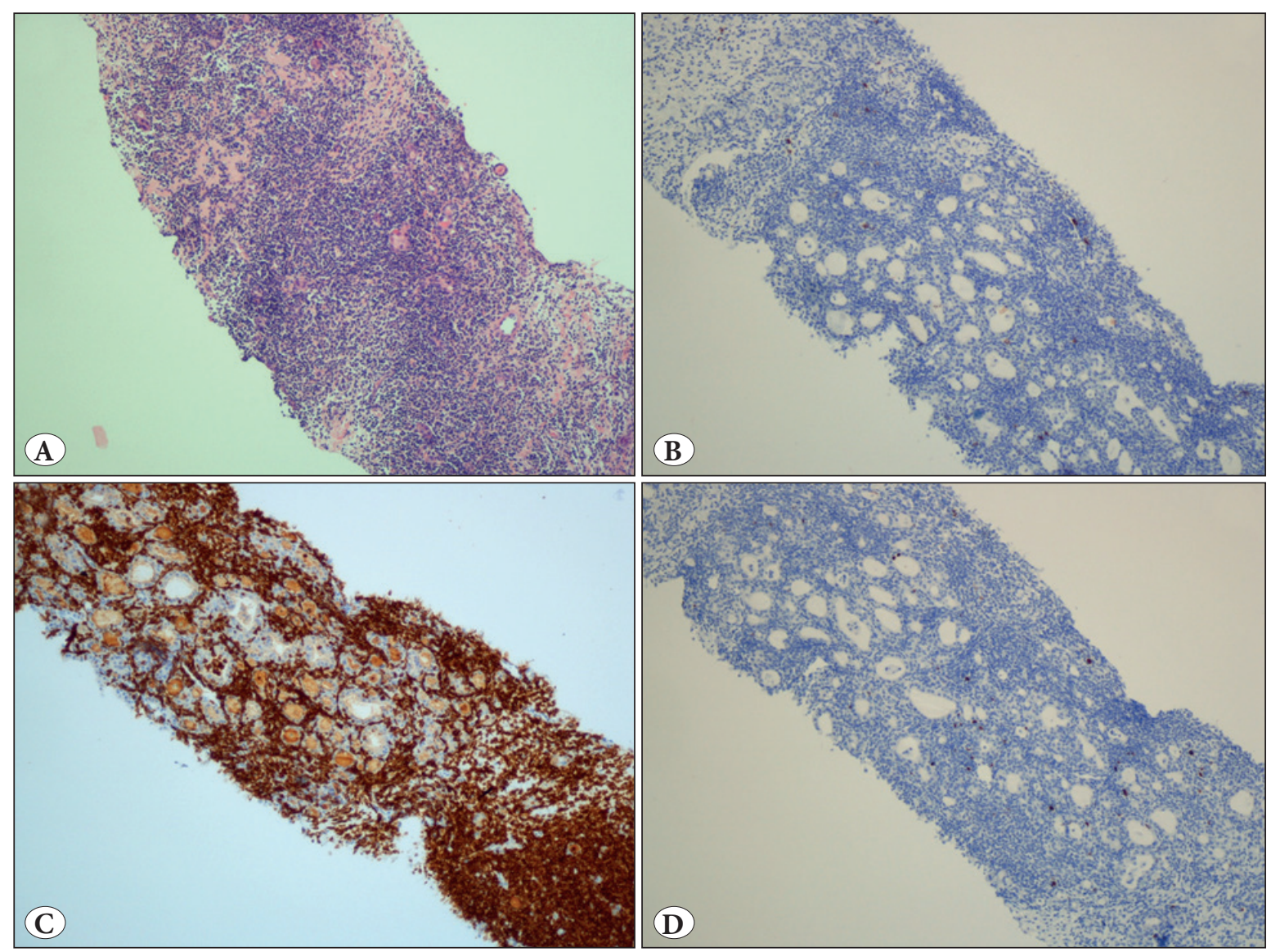

Figure 3: A) Thyroid with small lymphocytes infiltration (H\&E; x100). B) Cells are CD20 negative (IHC; x100). C) Cells are CD3 positive (IHC; x100). D) Ki67 is less than $1 \%$ (IHC; x100).
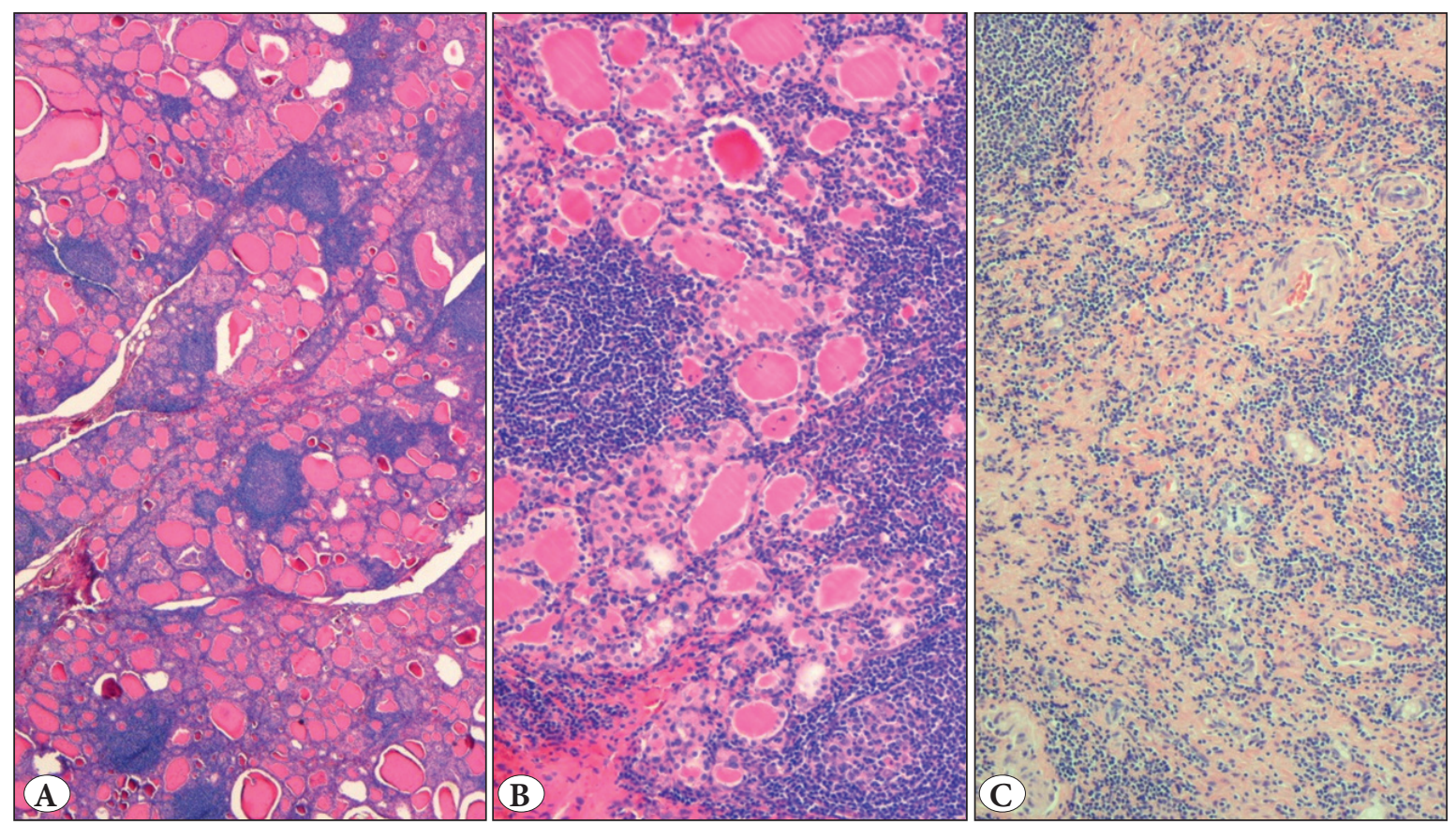

Figure 4: A-B) Thyroid showing features of thyroiditis with follicles of variable sizes and lymphoid clusters forming germinal centers (H\&E; x20, H\&E; x200). C) In some areas, fibrotic bands with lymphocytes are present (H\&E; x100). 


\section{CONFLICT of INTEREST}

The authors declare no conflict of interest.

\section{FUNDING}

The authors have not received funding from any organization.

\section{REFERENCES}

1. Chan JKC, Burke JS, Ferry JA, Wotherspoon A. Primary thyroid lymphoma. In: Lloyd RV, Osamura RY, Klöppel G, Rosai J, editors. WHO Classification of Tumours of Endocrine Organs. Lyon: WHO PRESS; 2017. 137-8.

2. Ghatalia P, Morgan CJ, Sonpavde G. Meta-analysis of regression of advanced solid tumors in patients receiving placebo or no anticancer therapy in prospective trials. Crit Rev Oncol Hematol. 2016;98:122-36.

3. Potts DA, Fromm JR, Gopal AK, Cassaday RD. Spontaneous remission of an untreated, MYC and BCL-2 coexpressing, highgrade B-cell lymphoma: A case report and literature review. Case Rep Hematol. 2017;2017:2676254.

4. Caturegli P, De Remigis A, Chuang K, Dembele M, Iwama A, Iwama S. Hashimoto's thyroiditis: Celebrating the centennial through the lens of the Johns Hopkins Hospital surgical pathology records. Thyroid. 2013;23: 142-50.

5. Rosai J, Tallini G. Thyroid gland. In: Juan Rosai, editor. Rosai and Ackerman's surgical pathology. 10th ed. Edinburgh: Elsevier. 2011. 492-5.
6. Chai YJ, Hong JH, Koo DH, Yu HW, Lee JH, Kwon H, Kim SJ, Choi JY, Lee KE. Clinicopathological characteristics and treatment outcomes of 38 cases of primary thyroid lymphoma: A multicenter study. Ann Surg Treat Res. 2015;89: 295-9.

7. Lai X, Xia Y, Zhang B, Li J, Jiang Y. A meta-analysis of Hashimoto's thyroiditis and papillary thyroid carcinoma risk. Oncotarget. 2017;8: 62414-24.

8. Cole WH, Everson TC. Spontaneous regression of cancer: Preliminary report. Ann Surg. 1956;144: 366-83.

9. Jessy T. Immunity over inability: The spontaneous regression of cancer. J Nat Sci Biol Med. 2011;2: 43-9.

10. Sasaki J, Kurihara H, Nakano Y, Kotani K, Tame E, Sasaki A. Apparent spontaneous regression of malignant neoplasms after radiography: Report of four cases. Int J Surg Case Rep. 2016;25: 40-3.

11. Drobyski WR, Qazi R. Spontaneous regression in non-Hodgkin's lymphoma: Clinical and pathogenetic considerations. Am J Hematol. 1989;31:138-41.

12. Lim DH, Rhee JY, Park KW. Stage IV advanced diffuse large B-cell lymphoma in human immunodeficiency virus infection with achieving cure by using highly active antiretroviral therapy alone: A case report. Int J STD AIDS. 2017;28: 932-6.

13. Uohashi A, Imoto S, Matsui T, Murayama T, Okimura Y, Chihara $\mathrm{K}$, Ohbayashi C, Itoh $\mathrm{H}$. Spontaneous regression of diffuse largecell lymphoma associated with Hashimoto's thyroiditis. Am J Hematol. 1996;53: 201-2.

14. Andorsky DJ, Yamada RE, Said J, Pinkus GS, Betting DJ, Timmerman JM. Programmed death ligand 1 is expressed by non-Hodgkin lymphomas and inhibits the activity of tumorassociated T cells. Clin Cancer Res. 2011;17: 4232-44. 